\title{
Sociabilidade dos adolescentes em conflito com a lei de Uberlândia (MG) em 2017
}

\author{
Manuela Soares Silveira ${ }^{1}$ \\ Fabiane Santana Previtali ${ }^{1}$ \\ https://orcid.org/0000-0002-9465-1749 \\ https://orcid.org/0000-0002-8079-5557 \\ ${ }^{1}$ Universidade Federal de Uberlândia, Instituto de Ciências Sociais, Pós-Graduação em Ciências Sociais, Uberlândia, MG, Brasil
}

\section{Sociabilidade dos adolescentes em conflito com a lei de Uberlândia (MG) em 2017}

Resumo: O presente estudo apresenta resultados parciais de pesquisa de mestrado, que tem por objetivo analisar a sociabilidade dos adolescentes em conflito com a lei no município de Uberlândia (MG) no ano de 2017, mais especificamente os adolescentes do sexo masculino que cumprem medida socioeducativa de internação no Centro Socioeducativo de Uberlândia (CSEUB). Buscou-se então compreender quais os sentidos atribuídos pelos sujeitos às suas experiências sociais. Optou-se pelo materialismo histórico e dialético como base teórico-metodológica. Nesse sentido, parte-se de um recorte na sociabilidade dos sujeitos, no que diz respeito ao trabalho. Empreenderam-se a pesquisa bibliográfica para um amplo levantamento dos autores e de suas respectivas produções científicas, e a pesquisa de campo com um estudo de caso no CSEUB. A análise buscou inserir os participantes da pesquisa em um contexto macrossocietário, no que diz respeito à reestruturação produtiva e às novas configurações do mundo do trabalho, possibilitando compreender que os adolescentes aqui pesquisados e seu grupo social têm suas sociabilidades configuradas pelo sociometabolismo do capital, de modo a contribuir na reprodução e manutenção dessa estrutura.

Palavras-chave: Adolescente em conflito com a lei. Medida socioeducativa. Sociabilidade. Trabalho.

\section{Sociability of adolescents in conflict with the law in Uberlândia (MG) in 2017}

Abstract: This study presents partial results of a master's research that examines the sociability of adolescents in conflict with the law in the city of Uberlândia (MG) in 2017. The research focuses specifically on male adolescents who are in the city's juvenile center Centro Socioeducativo de Uberlândia (CSEUB). The aim is to understand the meanings the subjects attribute to their social experiences, using historical and dialectical materialism as a theoretical-methodological basis. The study is grounded on the sociability of the subjects around the work. As well as the field research at the CSEUB, a bibliographic review was conducted identifying the authors and their contribution to the literature on the issue. The analysis observed the subjects within a macro-social context, regarding the productive restructuring and new configurations of the world of work. This perspective allows understanding that the sociability of the adolescents observed in the context of the research (and their social group) is shaped by the socio-metabolism of capital, contributing to its reproduction and maintenance.

Keywords: Adolescent in conflict with the law. Socio-educational measure. Sociability. Work.

Recebido em 18.09.2018. Aprovado em 20.11.2018. Revisado em 19.04.2019.

C O(s) Autor(es). 2019 Acesso Aberto Esta obra está licenciada sob os termos da Licença Creative Commons Atribuição-NãoComercial 4.0 Internacional (https://creativecommons.org/licenses/by-nc/4.0/deed.pt_BR), que permite copiar, distribuir e reproduzir em qualquer meio, bem como adaptar, transformar e criar a partir deste material, desde que para fins não comerciais e que você forneça o devido crédito aos autores e a fonte, insira um link para a Licença Creative Commons e indique se mudanças foram feitas. 


\section{Introdução}

O estudo que aqui se propõe apresenta resultados parciais de pesquisa de mestrado ${ }^{1}$, a qual tem por objetivo analisar a sociabilidade dos adolescentes ${ }^{2}$ em conflito com a lei do município de Uberlândia (MG) no ano de 2017, mais especificamente os adolescentes do sexo masculino que cumprem medida socioeducativa de internação (em privação de liberdade) no Centro Socioeducativo de Uberlândia (CSEUB).

Busca-se estabelecer aqui o recorte de classe dentro da categoria social da juventude, tendo em vista a forma como é vivenciada a condição de ser jovem por parte dos adolescentes da pesquisa. Dessa forma, estão inseridos em uma juventude específica, aquela da classe trabalhadora em conflito com o capital: a juventude da classe trabalhadora.

Assim, identifica-se o reflexo das expressões da questão social ${ }^{3}$ em suas vivências, produzidas pela estrutura social e econômica, bem como o não pertencimento, e a denegação e ausência de direitos, contribuindo para sua atual condição de adolescente em conflito com a lei. Há, portanto, uma reprodução da violência, como forma de resistência, de pertencer e ser alguém.

Por isso a importância e urgência de se pesquisar a sociabilidade do adolescente autor de ato infracional ${ }^{4}$, buscando compreendê-la a partir dos significados e sentidos atribuídos pelos próprios sujeitos, seus familiares, e os operadores do programa de atendimento ${ }^{5}$ ao adolescente em cumprimento de medida socioeducativa.

Acredita-se que por ser um momento de constituição da subjetividade, da identidade, e de formação, os adolescentes têm grandes possibilidades de transformação e de construção de novas trajetórias. Assim, o processo de investigação aqui estabelecido, tem uma finalidade social maior do que simplesmente a produção de dados, mas especialmente a de dar voz e espaço a sujeitos muitas vezes silenciados, estigmatizados e punidos por sua condição social, escancarando sua realidade, vivências e experiências, a partir de sua própria perspectiva. Por isso, os resultados trazidos por essa pesquisa não necessariamente traduzem uma realidade mais abrangente, mas mostram, por meio de um estudo de caso local, a importância e necessidade de novas pesquisas que reforcem e ampliem o que aqui se busca mostrar.

$\mathrm{O}$ recorte aqui proposto, no aspecto que diz respeito à sociabilidade e trabalho, segue o que traz $\mathrm{o}$ Estatuto da Criança e do Adolescente (ECA) (BRASIL, 2015) como direitos fundamentais ${ }^{6}$ do adolescente, inclusive aquele autor de ato infracional, bem como constituintes dos eixos ${ }^{7}$ da medida socioeducativa.

A partir daí, empreendeu-se primeiramente a pesquisa bibliográfica na busca de um amplo levantamento dos autores e de suas respectivas produções científicas que fossem condizentes com o referencial e com a problemática proposta. Para a pesquisa de campo, com o objetivo de conhecer as formas de sociabilidade e relações sociais em que estão inseridos os adolescentes que cometeram atos infracionais em Uberlândia (MG), no ano de 2017, escolheu-se o CSEUB em função da maior concentração de adolescentes autores de ato infracional em cumprimento de medida socioeducativa, já que é o único local que atende adolescentes de toda a região do entorno da cidade de Uberlândia em regime fechado, e, em decorrência do acautelamento, o contato com o adolescente e seus familiares é melhor possibilitado.

Primeiramente realizou-se a pesquisa documental, para possibilitar uma maior familiarização com o espaço de pesquisa, conhecendo melhor o funcionamento, normas, regras e rotina da instituição, além de se aproximar do perfil do adolescente do CSEUB e de seus familiares, para que a observação, e, posteriormente, as entrevistas, tivessem uma base de informações essenciais que orientem seu planejamento. Posteriormente, a observação simples foi realizada com caráter exploratório, para coleta de dados acerca da realidade e da cotidianidade dos sujeitos.

A partir dessas duas primeiras fases, foram definidos os participantes da pesquisa. No que diz respeito aos adolescentes, num primeiro momento, foram selecionados aqueles que haviam participado das atividades acompanhadas durante a fase de observação. Para fazer o convite para a pesquisa, bem como pegar a autorização para aqueles que têm menos de 18 anos com o seu responsável, utilizou-se um dia de visita familiar (que ocorre às terças-feiras).

Durante a abordagem, de forma rápida e sucinta, para que o momento de visita não fosse muito afetado, foram explicados os objetivos da pesquisa, informados da liberdade de não participação da mesma, bem como das questões éticas de sigilo e de proteção da identidade de todos os pesquisados, deixando claro que em nenhum momento eles seriam identificados, nem mesmo durante a publicação dos resultados. As entrevistas com os adolescentes foram realizadas no espaço da instituição, nas salas de atendimentos individuais.

Para o recorte aqui apresentado, importa dizer que foram entrevistados oito adolescentes, com os quais utilizou-se a entrevista semiestruturada que, direcionando para os aspectos específicos a serem tratados dentro de sua sociabilidade, dá liberdade ao entrevistado de discorrer sobre o tema em questão, independente das 
perguntas formuladas, possibilitando a reflexão do próprio sujeito sobre a realidade que vivencia, para que ele possa colocar suas percepções sobre essa mesma realidade.

Tendo em vista o cunho qualitativo da pesquisa, a qual tem por universo as representações, conhecimentos, práticas, comportamentos e atitudes dos participantes da pesquisa, bem como sua configuração em um estudo de caso local, não há como definir uma quantidade de indivíduos que seja representativa desta totalidade. Por isso não se recorreu a outros adolescentes para ampliar a quantidade de entrevistados, seguindo a orientação de Minayo, Deslandes e Gomes (2009, p. 48) para esse tipo de pesquisa social: a quantidade de entrevistados segue o critério da saturação, "[...] quando as concepções, explicações e sentidos atribuídos pelos sujeitos começam a ter uma regularidade de apresentação". É importante ressaltar que os dados e análises trazidos pelas entrevistas com os familiares e profissionais da instituição não foram registrados no presente artigo, mas constam na dissertação de mestrado que o fundamenta (SILVEIRA, 2018).

Parte-se do entendimento de que o estudo não precisa necessariamente abranger a totalidade das falas e expressões dos interlocutores, tendo como foco a exploração do conjunto de opiniões e representações sociais sobre o tema que pretende investigar, mas ao mesmo tempo dando conta da diversidade de opiniões e crenças dentro de um mesmo segmento social.

Como forma de garantir o sigilo das entrevistas, bem como a preservação da identidade dos entrevistados utilizamos aqui um código para referenciar as falas, o qual foi definido também com o objetivo de registrar e garantir a memória das oito crianças e adolescentes mortos no Massacre da Candelária, do ano de $1993^{8}$. Esses nomes serão utilizados como nomes fictícios, para referenciar os relatos trazidos pelos adolescentes entrevistados e seus familiares, garantindo o sigilo de suas identidades. Além disso, quando aparecer nas falas algum dos nomes, será colocada uma tarja como essa: , também para garantir o sigilo.

Em todo o processo de construção da pesquisa optouse por uma base teórico-metodológica que se contrapõe à visão naturalista e determinista da realidade: o materialismo histórico e dialético de Marx. Tendo em vista a intenção primária de colocar em realce a realidade concreta dos adolescentes aqui pesquisados, buscando conhecê-la e compreendê-la, a escolha dessa base vai possibilitar tal orientação de forma mais conectada ao real. Isso porque ela não considera os sentidos, significados, pensamentos, de forma abstrata, mas sim como parte e produto da realidade concreta, por ela determinados, bem como pelas necessidades materiais. O conhecimento da sociabilidade dos adolescentes em conflito com a lei, em suas particularidades, pressupõe inicialmente o conhecimento e a compreensão das relações sociais e de produção em que esses sujeitos estão inseridos, numa perspectiva macrossocietária, a qual vai ser essencial para a reprodução da estrutura e dinâmica do objeto de estudo, com veracidade no plano ideal.

A partir desse caminho metodológico, pode-se compreender a sociabilidade do adolescente em conflito com a lei enquanto conceito abstrato e identificamos algumas de suas diversas determinações ${ }^{9}$. Entre essas estão especialmente aquelas econômico-sociais, no que diz respeito, por exemplo, ao trabalho no sociometabolismo do capital. Por isso, busca-se a compreensão do contexto macrossocietário dessa sociabilidade, com a reestruturação produtiva, a flexibilização e precarização do trabalho, para então se retornar ao concreto já cheio de determinações, com a pesquisa de campo e a investigação teórica e empírica, que está entre o ponto de partida e o de chegada (que é a pesquisa propriamente dita). E esse ponto de chegada é um próximo ponto de partida, a investigação não se esgota.

Sendo assim, tem-se como objetivos desse estudo conhecer as formas de sociabilidade e relações sociais em que estão inseridos os adolescentes em conflito com a lei do CSEUB - Uberlândia (MG) durante o ano de 2017, antes e durante sua responsabilização penal, especialmente no que diz respeito ao trabalho; compreender essa realidade na perspectiva dos significados e sentidos atribuídos pelos próprios sujeitos; identificar as estratégias de sobrevivência encontradas pelos adolescentes entrevistados, antes e durante sua responsabilização penal.

Partindo dessas considerações, organiza-se a apresentação da presente pesquisa no esforço de inserir seus participantes em um contexto macrossocietário, focando especialmente nos aspectos do trabalho, no que diz respeito à reestruturação produtiva e às novas configurações do mundo do trabalho, à situação da juventude da classe trabalhadora no Brasil e como esses processos redefinem e reconfiguram as sociabilidades dos jovens do CSEUB. 


\section{Juventude da classe trabalhadora, sociabilidade e trabalho}

A crise do capital dos últimos 30 anos do século XX, e que se estende até os dias atuais, acarretou profundas mudanças na sociabilidade humana, tanto na esfera da materialidade como da subjetividade, tendo sua expressão mais contundente no interior do mundo do trabalho, a partir, especialmente, do neoliberalismo e da reestruturação produtiva ${ }^{10}$ (ANTUNES, 2002). As principais transformações nesse âmbito, como aspectos constitutivos dessa fase da reestruturação produtiva do capital, foram o desemprego, a precarização, a flexibilização e a terceirização do trabalho, as quais surgem como ações remediadoras que o próprio capital oferece para os problemas decorrentes de sua expansão (MÉSZÁROS, 2011).

Então busca-se somente reestruturar a crise minimizando por algum tempo os efeitos danosos que surgem, mas não se atinge de fato a causa estrutural, os pilares, as bases causais do modo de produção capitalista historicamente há muito estabelecidas (ANTUNES, 2002; MÉSZÁROS, 2011).

É importante ressaltar que as mudanças e a flexibilização na técnica e nos padrões de acumulação, trazidas pela reestruturação produtiva, não rompem, mas aprofundam a exploração do(a) trabalhador(a) pelo capital, uma vez que, conforme já postulava Marx (1996, p. 435), "[...] é impulso imanente e tendência constante do capital aumentar a força produtiva do trabalho para baratear a mercadoria e, mediante o barateamento da mercadoria, baratear o próprio trabalhador".

Esse quadro atinge não só os países capitalistas centrais, como a Inglaterra, a Alemanha, o Japão e os EUA, mas também aqueles do chamado Terceiro Mundo, como o Brasil. Entretanto, nesses últimos, a chamada reestruturação produtiva se deu de forma subordinada, dependente e subalterna, o que reflete sua inserção na economia capitalista mundial. Assim, a América Latina está designada para as etapas inferiores da produção industrial dentro da nova divisão internacional do trabalho. Para os centros imperialistas são destinadas as etapas mais avançadas como, por exemplo, a produção de computadores e a indústria eletrônica pesada em geral, a exploração de novas fontes de energia, como a de origem nuclear etc. (MARINI, 2005).

Os reflexos dessas transformações se consubstanciam de imediato no mundo do trabalho. No Brasil, os reflexos da reestruturação produtiva e da implementação de um projeto neoliberal se mostram como agravamento de problemas que são estruturais do capitalismo dependente existente no País, como a precarização do trabalho.

Alves (2014) identifica dois modelos de desenvolvimento capitalista implementados no Brasil nas últimas três décadas: o neoliberalismo e o neodesenvolvimentismo, que apesar de compor um processo desigual, garantem, ambos, a afirmação da ordem burguesa no Brasil, visando instaurar um novo regime de acumulação do capital em sua etapa de crise estrutural. O modelo neoliberal foi implementado pelo governo de Fernando Henrique Cardoso (1995-2002), cuja agenda se orientou pelo trinômio: abertura econômica, privatizações e desregulamentação do Estado, marcada por transferências gigantescas de recursos públicos para a iniciativa privada (ALVES, 2014).

Buscando responder às fragilidades e aos limites da economia neoliberal global que se refletiram na América Latina, o governo Luís Inácio Lula da Silva (2003-2010) trouxe consigo a necessidade de construção de outro modelo de desenvolvimento capitalista alternativo às políticas neoliberais, o qual Alves (2014) identifica como neodesenvolvimentismo. De um lado, estabelece a parceria do Estado com o mercado, que atribui ao primeiro o papel de indutor da economia capitalista no Brasil, possibilitando o novo patamar de acumulação do capital, enquanto, por outro, busca a redução da desigualdade de renda no País, permitindo redistribuir renda, ampliar o mercado de consumo e instaurar suportes sociais mínimos de existência para a classe trabalhadora pobre (ALVES, 2014).

Entretanto, apesar dos avanços trazidos pelos indicadores sociais positivos, Alves (2014) explica que, contraditoriamente, é na década de 2000 que a denominada superexploração da força de trabalho ${ }^{11}$ se aprofunda e toma novas formas sociais e históricas, não mais somente na indústria, mas nos serviços e na administração pública.

O que se percebe nesse quadro é que, segundo Alves (2014), há uma persistência de traços que são históricos e estruturais no Brasil, aprofundando a já existente degradação do trabalho no País, por meio de aspectos como:

[...] o aumento da taxa de rotatividade do trabalho e o crescimento dos contratos de trabalho precário por conta das novas modalidades de contratos de trabalho flexíveis, inscritas na CLT, com a expansão da terceirização e do emprego subcontratado (assalariados contratados em serviços terceirizados). (ALVES, 2014, p. 52).

Assim, as altas taxas de desemprego, a informalidade e a desproteção social, os achatamentos assalariais, que se desdobram especialmente no setor de serviços, vão se mostrar como aspectos que compõem essa nova precariedade do trabalho brasileiro, aprofundando a superexploração da força de trabalho que é estrutural nesse País. Superexploração que atinge de forma mais intensa e recrudescida grupos sociais específicos como a juventude da classe trabalhadora. 
Segundo a Pesquisa Nacional por Amostra de Domicílios (PNAD) do ano de 2015, do Instituto Brasileiro de Geografia e Estatística (IBGE) ([2015?]), 29,88\% (48.345.000 pessoas) da população brasileira com mais de 15 anos (161.792.000 pessoas) - e, portanto, legalmente apta para o trabalho - eram jovens com idade entre 15 e 29 anos. Desses, $64,48 \%$ (31.171.000 pessoas) compunham a população economicamente ativa ${ }^{12}$. Assim, a situação do trabalho da juventude na década considerada (2005-2015), se destoando do quadro geral, se mostra negativa para esse segmento, havendo uma diminuição do número de jovens economicamente ativos (queda de 12,8\%), acompanhada da redução na ocupação desses mesmos jovens em 15,41\% (INSTITUTO BRASILEIRO DE GEOGRAFIA E ESTATÍSTICA, [2005?], [2015?]). Dessa forma, a precarização do trabalho afeta de forma mais intensa essa parcela da população, que, de acordo com o Departamento Intersindical de Estatística e Estudos Socioeconômicos (DIEESE) (2012, p. 240), tem "[...] maior dificuldade para encontrar e manter uma ocupação e, por isso, representam uma parcela expressiva do exército de desempregados que pressiona o mercado de trabalho".

Alguns dados das regiões metropolitanas ${ }^{13}$ trazidos pelo DIEESE (2012) são ilustrativos desse quadro, ainda que sejam de um período anterior (1999-2009), pois possibilitam uma contextualização da situação em que estão inseridos esses jovens. Com exceção da região metropolitana de Salvador, nas demais regiões de $5,3 \%$ a $12,1 \%$ do total de jovens estudantes (de 16 a 24 anos de idade), conforme a região, procuravam por emprego. Entretanto, uma parcela desses jovens que varia entre $25 \%$ e $39 \%$ nas sete regiões pesquisadas, apenas procura trabalho, sem estudar.

Essa realidade pode ser decorrente das dificuldades que esses sujeitos devem enfrentar para conciliar as longas jornadas que lhes são exigidas no trabalho, com os estudos, o que se mostra, segundo o DIEESE (2012), como uma das principais razões para o abandono da escola. A precarização da situação desses sujeitos se mostra quando, por um lado, no período de 1999 a 2009, com exceção de Porto Alegre, reduziu-se a proporção de jovens que estudavam, e por outro aumentou a proporção daqueles que não desenvolviam qualquer atividade de trabalho ou educacional, podendo estar em situação de desemprego ao mesmo tempo que em desqualificação educacional.

No que diz respeito ao tipo de ocupação, a proporção de jovens assalariados no setor privado que não tinham a carteira assinada em 2009 nas regiões metropolitanas foi duas vezes maior do que aquela observada na população em geral. Por outro lado, a inserção desse grupo no trabalho autônomo é menor em comparação com os adultos, por isso "[...] o emprego informal entre os jovens ocorre principalmente na forma do assalariamento sem carteira de trabalho assinada, mais do que na forma do trabalho autônomo". (DEPARTAMENTO INTERSINDICAL DE ESTATÍSTICA E ESTUDOS SOCIOECONÔMICOS, 2012, p. 245).

Conforme o mesmo estudo do DIEESE (2012) a rotatividade também se mostra como um problema que se aprofunda nesse grupo em específico. O vínculo de emprego e de ocupação tem duração mais curta entre os jovens, um quarto da duração média do total de ocupações. Ainda que submetidos às longas jornadas de trabalho, a remuneração dos jovens ainda se mostra mais baixa do que para o conjunto da população, embora no período tenha havido um avanço relativamente maior nessa remuneração, que se elevou como proporção da remuneração média dos ocupados.

Uma das causas para o desemprego juvenil pode se dar na questão do primeiro emprego. A exigência de trabalhadores com experiência profissional pode ter acarretado maior dificuldade para a inserção da juventude, especialmente no primeiro emprego, que se aprofundou ao longo da década de 2000 , principalmente entre os jovens de 18 a 24 anos de idade:

No início da década, um quinto das admissões resultava do primeiro emprego e, ao final da década, essa participação recuou sensivelmente. Nas faixas etárias de idade mais baixa, nas quais a participação do primeiro emprego é significativa, houve um aumento na participação entre os muito jovens (até 17 anos de idade), pois nesse segmento, $74 \%$ das admissões, em 2009 , ocorreram por primeiro emprego. Além disso, houve um recuo entre os jovens de 18 a 24 anos, para os quais o primeiro emprego encerrou a década com $28 \%$ de participação. (DEPARTAMENTO INTERSINDICAL DE ESTATÍSTICA E ESTUDOS SOCIOECONÔMICOS, 2012,p. 86).

Partindo dessas reflexões, é preciso localizar no contexto analisado os adolescentes autores de ato infracional, compreendendo sua sociabilidade em suas especificidades e particularidades.

\section{A sociabilidade dos adolescentes do CSEUB: trabalho}

A pesquisa de campo com as entrevistas com oito adolescentes internos da instituição delineou um quadro de não garantia e denegação de direitos, inclusive do direito ao trabalho, mostrando uma realidade não 
só de precarização, mas também de exclusão e estigmatização dos sujeitos aqui pesquisados. Por isso a apresentação de seus relatos se faz importante, especialmente por mostrar a percepção dos próprios adolescentes acerca de sua sociabilidade, suas vivências e experiências.

Somente dois entrevistados nunca trabalharam, mas daqueles que estavam trabalhando antes da privação de liberdade, ou que já trabalharam em algum momento, nenhum esteve inserido em trabalhos formais, com carteira assinada. Segundo relatos desses entrevistados, esses trabalhos foram bicos, como serralheria, entregar panfleto, entregar placa de governo, servente, pintor, lava-jato, entregar ração e ajudante de carpinteiro, sendo que alguns deles trabalharam em mais de um. Isso atesta a rotatividade e instabilidade a que estão sujeitos esses adolescentes em seus empregos, levando a uma precarização não só do seu trabalho, mas de si mesmos. Além disso, outros trabalharam também em serviços de colaboração com a família, o que nem sempre era uma garantia de remuneração, principalmente em oficinas de carro.

O que se percebe é que o trabalho em família é visto como algo positivo, como uma herança passada por gerações, da qual o adolescente se sente parte e tem orgulho de ter aprendido. Entretanto, conforme seus relatos, o trabalho a que tiveram acesso, não somente os adolescentes, mas seus familiares, são trabalhos manuais ${ }^{14}$, que por sua inserção subalterna na divisão do trabalho reproduzem uma estrutura desigual de classes na qual esses sujeitos se encontram nos estratos mais baixos, situação que se mantém por diferentes gerações.

Isso se reforça nos relatos, que mostram que nem sempre a percepção acerca do trabalho é positiva, percepção que se delineia em diversos contornos nas falas trazidas pelos sujeitos. Um problema candente mostrado em uma das falas é a maior dificuldade que a juventude tem de conseguir empregos:

Por causa que cê chega lá tudo pra eles tem que ser de maior, tudo é de maior, de maior, de menor também dá conta de trabalhar uai. Meu irmão, tenho dois irmão de maior, meus dois irmão não é envolvido no crime, um tem 19 o outro tem 21, os dois, o meu irmão de 21 é pedreiro, ele me levava pra trabalhar, chegava na minha mãe falava desse jeito "o __ trabalha bem melhor do que o __", que é o meu outro irmão que, que tem 19, "tem muito mais disposição”. Aí eles ficam tirando nós como nós fosse de menor, tipo eu acho, tipo que não vai dar conta né, um negócio assim. (LEANDRO).

Acredita-se que essa dificuldade pode ser reflexo da exigência de trabalhadores com maior experiência para novas contratações, que tem obstaculizado, como vimos, a inserção de jovens no mercado de trabalho, especialmente no primeiro emprego. Pode ser reflexo também das transformações no mundo do trabalho que têm afetado de forma mais intensa esse grupo social. Além disso, é possível que essas experiências vivenciadas pelo adolescente tenham sido fruto de atitudes estigmatizantes e preconceituosas com sua condição social, as quais atingem esse grupo social como forma de controle e segregação.

Outra questão identificada pelos sujeitos são os baixos salários oferecidos pelos trabalhos aos quais têm acesso, em decorrência de sua condição social, especialmente pela baixa escolaridade.

Desse jeito que é a minha vida, porque eu mesmo eu, tsc, eu tô de boa de tsc, ou tô cansado dessa vida sabe, mas ou, porque, ah não, mas eu, eu tsc, sair dessa vida também não vira não, porque se eu sair daqui eu vou começar a trabalhar, a trabalhar, estudar tsc. Ai eu vou ter meus trem que eu quero ter, que é um carro brabo, um carrinho de boa sabe, não é esses carrinho velho, golzinho, corsinha, quero ter um carro tipo uma navinha que as muié já, novinho pá, paga tipo uma madeirinha já [risos]. Porque que nem, eu querendo ou não, esse trem que eu faço é errado, mas eu ganho dinheiro fácil. (GAMBAZINHO).

[...] aí eu fui e comecei a levantar de novo né, depois disso eu comecei a vender droga mesmo, aí eu comecei a ganhar dinheiro mesmo, a ficar mais tempo de madrugada vendendo. [...] porque o crime tem hora que também é mordomia, cê ganha altos dinheiro sô, cê ganha assim 3 mil num dia, você fala "Vixe!". Um trabalhador aí demora 2 meses pra ganhar 3 mil, 1 mês. (MARCELO).

O que se percebe em suas falas é que eles entendem que o trabalho que conhecem, no qual foram inseridos juntamente com suas famílias, não oferece o mesmo nível socioeconômico e o estilo de vida possibilitado pelo dinheiro que eles conseguem no crime. Essa é uma fala recorrente em praticamente todas as entrevistas, o que mostra como os valores fetichizados e alienados da sociabilidade do capital podem ter conformado o sentido que o trabalho tomou para esses sujeitos. Fruto também da divisão do trabalho, conforme explicam Marx e Engels (2011), que destina para esses indivíduos a produção, fazendo com que o consumo deva ser garantido por outras vias que não o trabalho.

Assim, o trabalho que não supre as necessidades próprias a esse estilo de vida propagado pelos valores capitalistas passa a ser autossacrifício e mortificação. É trabalho forçado, obrigatório, como diz 
Marx (2004b), e esses sujeitos deixam de se sentir livres e ativos em suas funções genuinamente humanas. Não se trata de um trabalho, mas de um aborrecimento total, com o enfraquecimento das forças físicas e morais (ENGELS, 2008).

Acreditamos que isso seja fruto da sociabilidade configurada em tempos de neoliberalismo e reestruturação produtiva, a qual exige uma busca individualista e desenfreada por um estilo de vida consumista, mas não dá condições estruturais e sociais para o acesso universal a ele, responsabilizando o indivíduo por seu insucesso nessa busca. Sendo assim, por um lado o consumo permite o sentimento de cidadania, identidade e pertencimento, mas por outro é expressão e base da ordem sociometabólica do capital, conforme explica Alves (2014).

Essa percepção mais crítica também foi construída pelos sujeitos da pesquisa, que identificam a falta de oportunidades nas trajetórias por eles construídas.

\begin{abstract}
Mas intenção de mudar todo mundo tem, só falta só oportunidade, que isso é muito pouco pra nós, é muito pouco oportunidade. Porque muita pessoa tira nós, cê chega lá pra arrumar um serviço, nem sabe se você trabalha, se você, se você trabalha mesmo, se você quer, tira nós, tipo fala que não tem serviço pra nós, ai não quer que nós envolve ni crime, tipo o governo, esses negócios, não quer que nós envolve em crime, não quer que nós, quer que nós estuda, mas pra parar pra pensar nós também tem nossa vida uai, nós também quer ter uma roupa, nós também quer ter um tênis, nós quer ter um celular bom né, quer ter, nós também quer ter as coisas. (LEANDRO).
\end{abstract}

Essa fala traz o reflexo das relações desiguais de classe, em que determinado grupo social é excluído e segregado de um modo de vida que se torna posse de uma só classe. Assim, aos jovens mais favorecidos é direito o acesso a bens de consumo pessoais, como tênis, roupa e celulares. Essa exclusão e segregação de um grupo social de uma vivência consumista, como manifestação da questão social, a partir da apropriação privada da produção social e coletiva, é também consequência do estranhamento, como propõe Marx (2004a, p. 86, grifo do autor):

Se o produto do trabalho não pertence ao trabalhador, um poder estranho [que] está diante dele, então isto só é possível pelo fato de [o produto do trabalho] pertencer a um outro homem fora o trabalhador. Se sua atividade lhe é martírio, então ela tem de ser fruição para um outro e alegria de viver para um outro. Não os deuses, não a natureza, apenas o homem mesmo pode ser este poder estranho sobre o homem.

Se a fruição e alegria de viver cabem aos detentores do produto do trabalho, aos jovens da classe trabalhadora resta (tentar) se inserir em um mercado de trabalho precário e excludente, por meio do qual dificilmente se sentirão pertencentes a esse modo de vida. No caso dos jovens aqui pesquisados, sem entrar no mérito dessa questão, procuram alternativas, entre as quais está o cometimento de atos infracionais. Essa alternativa não se coloca como algo positivo, como se vê na fala de Gambazinho, que disse estar cansado dessa vida, mas que sair dela também não é uma solução. É o que diz também Leandro:

Trabalhava de servente. E questão de disposição pra trabalhar eu sempre tive, sempre tive, desde moleque, pintor, trabalhei no lava jato... soltava o crime e voltava, soltava, voltava, soltava pra trabalhar, $e$ eu trabalhava e o serviço acabava, ai ficava sem dinheiro [...]. Ai é na onde que eu ia pro crime de novo conseguir o dinheiro né, que é o dinheiro fácil, mas some fácil também.

Entretanto, o consumo de bens não é o único problema identificado pelos adolescentes. $\mathrm{O}$ trabalho enquanto fonte de renda se coloca para eles também como questão de sobrevivência.

Não, eu acho que a coisa mais é oportunidades né, se o cara quer mesmo pode ser até de lixeiro, o cara vai né, mas em mente, mente o que eu quero não tem não, o que aparecer, tem que trabalhar né, se não vorta, sem dinheiro vorta. E eu tô de boa, já sou de maior já, é pro outro lado da esquina ali ó ${ }^{15}$, e eu tô de boa. (VALDEVINO).

Pode-se notar nessa fala que há por parte do adolescente um entendimento de que ele não tem muitas possibilidades de escolha, caso ele queira trabalhar e não voltar para o crime e ser preso agora como adulto. Segundo ele, é preciso aceitar a oportunidade que aparecer, seja ela qual for. Essa percepção é reflexo de determinações existentes na realidade concreta, em que é destinado para a classe trabalhadora e sua juventude o caminho da vinculação ao mercado de trabalho para sua sobrevivência, por meio de trabalhos manuais, que são socialmente desvalorizados, seja em condições de trabalho ou de remuneração. 
Marx e Engels (2011) explicam esse caminho pela divisão desigual do trabalho, na qual a esfera de atividade e especialização na mesma, destinada exclusivamente a cada indivíduo, é a ele imposta, e dificilmente pode ele dela sair, para não perder os meios de subsistência.

A força de trabalho em ação, o trabalho mesmo, é, portanto, a atividade vital peculiar ao operário, seu modo peculiar de manifestar a vida. Eé esta atividade vital que ele vende a um terceiro para assegurar-se dos meios de subsistência necessários. Sua atividade vital não lhe é, pois, senão um meio de poder existir. Trabalha para viver. Para ele próprio, o trabalho não faz parte de sua vida; é antes um sacrifício de sua vida. [...] $o$ produto de sua atividade não é também o objetivo de sua atividade. [...] O que ele produz para si mesmo é o salário. (MARX; ENGELS, 2011, p. 30, grifo nosso).

Ainda nesse contexto, o trabalho aparece para os entrevistados também como possibilidades de sair da rua (sic), ocupar a mente (sic), ou seja, como alternativa à prática de atos infracionais, bem como para uma mudança de vida, uma forma de ganhar dinheiro na honestidade (sic). Esse valor é bem recorrente em todos os relatos, como uma contraposição ao ato infracional.

Ah, eu mudando de vida né primeiramente, arrumando um trabalho honesto e seguindo a minha vida, eu acho que a minha mãe ficaria feliz se eu seguisse a minha vida trabalhando honesto sabe, ver que eu tô pegando firme, que eu tô tentando buscar algo pra minha vida assim, eu acho que assim que ela ia se sentir mais feliz, vendo desse jeito entendeu? Isso ia deixar ela bastante feliz. (PAULO ROBERTO).

Mas vamo, eu vou conquistar é de outro jeito agora, trabalhando, nem que eu ganho pouco, mas eu vou juntando aí ó, rapidinho eu tô com os meus negocinho, negócio é embaçado. (MARCELO).

Assim, embora apareça como algo difícil, que traz infelicidade e mortifica o sujeito, o trabalho traz um sentido forte de honestidade, uma forma de ser alguém na vida (sic) e dar orgulho para suas famílias. Entretanto, é possível compreender que suas falas traduzem um discurso incutido nesses sujeitos por meio da educação que eles têm recebido pelas diversas instituições de socialização (como a família, a escola e o CSEUB), o qual pode levar ao conformismo com a estrutura social. Assim, acreditando que o dito trabalho honesto é a garantia de civilidade e de inserção social, ainda que ele não lhes permita nenhuma possibilidade de ascensão social, esses adolescentes reproduzem um discurso de conformismo e contribuição na reprodução da ordem social desigual e opressora.

O trabalho assalariado aparece nos discursos dos adolescentes como condição de civilidade, bem como em contraposição, como superação ao ato infracional. Tal sentido percebido pelos sujeitos é, mais uma vez, reflexo do estranhamento, o qual não se dá somente em relação ao objeto do trabalho, mas do próprio trabalhador, levando à perda de si mesmo, do seu mundo interior, o trabalhador vai deixando de pertencer a si próprio e passa a pertencer ao objeto (MARX, 2004a).

Sendo assim, somente como trabalhador é que pode existir, ao se apropriar do mundo externo, da natureza sensível. Então, essa relação vai se dar de forma estranhada e servil: "O auge desta servidão é que somente como trabalhador ele [pode] se manter como sujeito físico e apenas como sujeito físico ele é trabalhador". (MARX, 2004a, p. 82, grifo do autor).

O trabalho se coloca como uma necessidade nas vidas desses sujeitos, ainda que corroída sua sociabilidade pela ganância do capitalismo, sendo determinado por diferentes objetivos, entre os quais comprar suas coisas próprias, ajudar a família, manter os vícios, e adquirir independência da família.

Porque que eu trabalhava? Ah, mais pela questão do dinheiro né de primeira coisa, mas o duro era o dinheiro. Depois, depois era comprar meus negocinho né, que eu sempre gostei de ter minhas roupas, meu tênis. Ajudar a minha mãe quando precisava, minha mãe não trabalhava, só a minha irmã, eu já ajudava ela também no que eu posso, sempre foi isso aí. Pra manter meus vícios, que eu também tenho meus vícios né. (VALDEVINO).

São necessidades que estão fortemente ligadas ao consumo, à reprodução de suas sociabilidades, e, portanto, despidas do sentido e da vontade propriamente humanos da teleologia do trabalho. Isso porque esses sujeitos só têm inserção social, só são vistos, só são alguém, só são cidadãos, alguém na vida, quando trabalham, quando são assalariados.

[...] o ladrão, o vigarista, o mendigo, o desempregado, o faminto, o miserável e o criminoso são figuras (Gestalten) que não existem para ela [economia nacional], mas só para outros olhos, para os do médico, do 
juiz, do coveiro, do administrador da miséria, fantasmas [situados] fora de seu domínio. As carências do trabalhador são assim, para ela, apenas a necessidade (Bedürfnis) de conservá-lo durante o trabalho, a fim de que a raça dos trabalhadores não desapareça. (MARX, 2004a, p. 92, grifo do autor).

O problema é que a precariedade salarial reduz a capacidade aquisitiva das massas assalariadas, intervertendo esses indivíduos em “[...] sujeitos-que-se-frustram”. (ALVES, 2014, p. 26). Assim, frustrados por esse objetivo que muitas vezes não é alcançado, esses sujeitos enxergam a necessidade de busca por alternativas, entre as quais a prática de atos infracionais.

O que diferencia o ser social do animal é justamente a atividade vital como objeto de sua vontade e consciência, por isso é um ser genérico e sua atividade é uma atividade livre e universal. Ao perder a relação com o ser genérico em relação consigo e com o outro, ao deixar de se reconhecer como um ser universal e livre, se efetiva o estranhamento, e o indivíduo encontra de forma alienada e deturpada essa realização na prática de atos infracionais.

\section{Considerações Finais}

Os estudos acerca da adolescência e o conhecimento de seus direitos e das normativas que os garantem programaticamente levaram à compreensão de que por serem pessoas em desenvolvimento, esses sujeitos apresentam potencialidades de transformação e construção de novos projetos societários, que permitam sua efetivação enquanto ser social. Por isso, apresentam demandas urgentes e prioritárias de intervenções que garantam de fato seu desenvolvimento, crescimento e emancipação.

Nesse sentido, a pesquisa buscou partir do concreto vivido, ir além das aparências imediatamente postas, não se destoando de uma realidade mais ampla e macrossocietária que é a ordem sociometabólica do capital, ainda que retratasse um estudo de caso local. Assim, a decisão de se realizar um estudo de caso no CSEUB não desconsiderou a inserção da instituição nessa ordem social, e por isso, também não intencionou demonstrar se há ou não emancipação e realização dos adolescentes enquanto seres sociais por parte do programa de atendimento ao adolescente. Sabe-se dos limites impostos pela estrutura social a esse intento. Por isso, procurou-se com o estudo de caso problematizar e demonstrar a vivência dos sujeitos nesse processo.

Sabe-se ainda que os estudos de caso carecem de validade externa, e, por isso, é preciso sempre ter cuidado com as conclusões neles baseadas. Aí a importância de se fundamentar em uma base teóricometodológica consistente, que traga as mediações necessárias para a compreensão dos resultados do estudo de caso em um contexto macrossocietário.

Assim é que o estudo de caso permitiu a confirmação da hipótese de que as sociabilidades dos jovens aqui pesquisados são permeadas por expressões da questão social manifestas na pobreza, nas vulnerabilidades, na (não) inserção precária no mercado de trabalho, na exclusão e no preconceito, para as quais a violência e o ato infracional tomaram sentidos de formas de resistência e sobrevivência. São, portanto, sociabilidades configuradas pelo sociometabolismo do capital, de modo a contribuir na reprodução e manutenção dessa estrutura.

\section{Referências}

ALVES, G. Trabalho e neodesenvolvimentismo: choque de capitalismo e nova degradação do trabalho no Brasil. Bauru: Canal 6, 2014. ANTUNES, R. Os sentidos do trabalho: ensaio sob a afirmação e a negação do trabalho. 6. ed. São Paulo: Boitempo, 2002.

BRASIL. Estatuto da criança e do adolescente: Lei n. 8.069, de 13 de julho de 1990, e legislação correlata. 13. ed. Brasília, DF: Edições Câmara, 2015. Disponível em: http://bd.camara.gov.br/bd/bitstream/handle/bdcamara/18403/estatuto_crianca_adolescente_13ed.pdf? sequence $=27$. Acesso em: 13 fev. 2017.

DEPARTAMENTO INTERSINDICAL DE ESTATÍSTICA E ESTUDOS SOCIOECONÔMICOS. A situação do trabalho no Brasil na primeira década dos anos 2000. São Paulo: DIEESE, 2012. Disponível em: http://www.dieese.org.br/livro/2012/ livroSituacaoTrabalhoBrasil.pdf. Acesso em: 7 out. 2016.

ENGELS, F. A situação da classe trabalhadora na Inglaterra. São Paulo: Boitempo, 2008.

IAMAMOTO, M. V. O Serviço Social na contemporaneidade: trabalho e formação profissional. 3. ed. São Paulo: Cortez, 2000. INSTITUTO BRASILEIRO DE GEOGRAFIA E ESTATÍSTICA. Pesquisa Nacional por Amostra de Domicílios. 2005. [Rio de Janeiro]: IBGE, [2005?]. Disponível em: http://www.ibge.gov.br/home/estatistica/populacao/trabalhoerendimento/pnad2005/default.shtm. Acesso em: 29 jun. 2017. 
INSTITUTO BRASILEIRO DE GEOGRAFIA E ESTATÍstICA. Pesquisa Nacional por Amostra de Domicílios. 2015. [Rio de Janeiro]: IBGE, [2015?]. Disponível em: http://www.ibge.gov.br/home/estatistica/populacao/trabalhoerendimento/pnad2015/default.shtm. Acesso em: 29 jun. 2017.

MARINI, R. M. Dialética da dependência, 1973. In: TRASPADINI, R.; STEDILE, J. P. (org.) Rui Mariano Marini: vida e obra. São Paulo: Expressão Popular, 2005. p. 137-180.

MARX, K. Manuscritos econômico-filosóficos. São Paulo: Boitempo, 2004a.

MARX, K. O capital: crítica da economia política: o processo de produção do capital. São Paulo: Nova Cultural, 1996. v. 1, t. 1. (Os Economistas).

MARX, K. Trabalho estranhado e propriedade privada. In: ANTUNES, R. (org.). A dialética do trabalho. São Paulo: Expressão Popular, 2004b. p. 141-160.

MARX, K.; ENGELS, F. Sistema de ensino e divisão do trabalho. In: MARX, K.; ENGELS, F. Textos sobre educação e ensino. Campinas, SP: Navegando, 2011. p. 25-40. Disponível em: https://www.marxists.org/portugues/marx/ano/mes/ensino.pdf. Acesso em: 28 set. 2017. MÉSZÁROS, I. Para além do capital: rumo a uma teoria da transição. São Paulo: Boitempo, 2011. Disponível em: https://nupese.fe.ufg.br/ up/208/o/para-alem-do-capital.pdf?1350933922. Acesso em: 9 ago. 2016.

MINAYO, M. C. de S. (org.); DESLANDES, S. F.; GOMES, R. Pesquisa social: teoria, método e criatividade. 28. ed. Petrópolis, RJ: Vozes, 2009. PAUlO NETTO, J. Capitalismo monopolista e serviço social. 5. ed. São Paulo: Cortez, 2006.

PAULO NETTO, J. Introdução ao estudo do método de Marx. São Paulo: Expressão Popular, 2011.

SAVIANI, D. Trabalho e educação: fundamentos ontológicos e históricos. Revista Brasileira de Educação, Rio de Janeiro, v. 12, n. 34, p. 152-165, jan./abr. 2007. Disponível em: http://www.scielo.br/pdf/rbedu/v12n34/a12v1234.pdf. Acesso em: 10 out. 2016.

SILVEIRA, D.; BOECKEL, C. Chacina da Candelária: sobrevivente ainda tem pesadelos, diz irmã. G1. Rio de Janeiro, 23 jul. 2015. Disponível em: http:/g1.globo.com/rio-de-janeiro/noticia/2015/07/chacina-da-candelaria-sobrevivente-ainda-tem-pesadelos-diz-irma.html. Acesso em: 27 jun. de 2017.

SILVEIRA, M. S. Sociabilidades e relações sociais dos adolescentes em conflito com a lei em Uberlândia/MG em 2017: sentidos e significados atribuídos pelos sujeitos. 2018. Dissertação (Mestrado em Ciências Sociais) - Programa de Pós-Graduação em Ciências Sociais, Universidade Federal de Uberlândia, Uberlândia, 2018.

\section{Notas}

1 Opresente artigo é recorte da dissertação de mestrado Sociabilidades e Relações Sociais dos Adolescentes em Conflito com a Lei em Uberlândia/ MG em 2017: sentidos e significados atribuídos pelos sujeitos de autoria de Manuela Soares Silveira, apresentada ao Programa de Pós-Graduação em Ciências Sociais da Universidade Federal de Uberlândia (PPGCS/UFU) sob orientação da Dra. Fabiane Santana Previtali (SILVEIRA, 2018).

2 OECA considera como criança a pessoa até doze anos de idade incompletos, eadolescentes aquela entre dozee dezoito anos de idade (BRASIL, 2015).

3 O uso do termo questão social é realizado no contexto dessa pesquisa conforme entende a tradição crítica marxista, que compreende seu complexo de causalidades para além da sua manifestação imediata como pauperismo, a identificando como contradição fundamental da sociedade capitalista. Fruto da relação de exploração capital/trabalho, a questão social passa a ser compreendida como corolário do desenvolvimento capitalista em todos os seus sentidos. Ou seja, sua existência, bem como suas manifestações são indissociáveis da reprodução dessa estrutura social. Ela se caracteriza por suas variadas expressões, tais como os indivíduos as experimentam cotidianamente no trabalho, na família, na área habitacional, na saúde, na assistência social pública etc. Por outro lado, ela é também fruto da rebeldia dos sujeitos que a vivenciam e a ela resistem e se opõem (IAMAMOTO, 2000; PAULO NETTO, 2006).

4 Conforme o ECA, é a conduta descrita como crime ou contravenção penal praticada por menores de dezoito anos por serem estes penalmente inimputáveis (BRASIL, 2015).

5 No presente artigo serão apresentados somente os resultados parciais das entrevistas realizadas com os adolescentes internos do CSEUB.

6 O art. $4^{\circ}$ do ECA diz que "É dever da família, da comunidade, da sociedade em geral e do poder público assegurar, com absoluta prioridade, a efetivação dos direitos referentes à vida, à saúde, à alimentação, à educação, ao esporte, ao lazer, à profissionalização, à cultura, à dignidade, ao respeito, à liberdade e à convivência familiar e comunitária”. (BRASIL, 2015, p. 11). Esses direitos são discorridos no Título II do ECA, Dos Direitos Fundamentais, do art. $7^{\circ}$ ao art. 69.

7 Conforme o Projeto Político Pedagógico do ano de 2015 do CSEUB, consultado em visita à instituição, os eixos da medida socioeducativa são a abordagem familiar e sociocomunitária, a educação escolar, as atividades artísticas, culturais, de lazer e oficinas socioeducativas, a formação básica para o trabalho e formação profissional, a inserção no mercado de trabalho e a saúde.

8 Na madrugada do dia 23 de julho de 1993, mais de 40 crianças e adolescentes dormiam nos arredores da Igreja da Candelária, no Centro da cidade do Rio de Janeiro, quando homens armados abriram fogo, promovendo um massacre que deixou oito meninos mortos: Paulo Roberto de Oliveira, 11 anos; Anderson de Oliveira Pereira, 13 anos; Marcelo Cândido de Jesus, 14 anos; Valdevino Miguel de Almeida, 14 anos; Gambazinho, 17 anos; Leandro Santos da Conceição, 17 anos; Paulo José da Silva, 18 anos; e Marcos Antônio Alves da Silva, 19 anos (SILVEIRA; BOECKEL, 2015).

9 “[...] determinações são traços pertinentes aos elementos constitutivos da realidade [...]. Por isso o conhecimento concreto do objeto é o conhecimento das suas múltiplas determinações - tanto mais se reproduzem as determinações de um objeto, tanto mais o pensamento reproduz a sua riqueza (concreção) real.” (PAULO NETTO, 2011, p. 45). 
10 Tendo como um dos seus aspectos principais a maquinofatura, caracterizada por Alves (2014), a reestruturação produtiva é uma nova forma de produção do capital, produto das revoluções tecnológicas dos últimos trinta anos, como a revolução informática e a revolução informacional.

11 O conceito de superexploração da força de trabalho foi desenvolvido por Ruy Mauro Marini (2005) para designar a forma como é garantida a acumulação capitalista nas economias dependentes, como as da América Latina, e, consequentemente, do Brasil. Para o autor, a superexploração da força de trabalho seria então um meio de aguçar os métodos de extração de trabalho excedente. Nega-se ao trabalhador as condições necessárias para repor o desgaste da sua força de trabalho, provocando seu esgotamento prematuro.

12 A População Economicamente Ativa (PEA) é a “[...] parcela da população que se encontra no mercado de trabalho na condição de ocupada ou desempregada [...]" (DEPARTAMENTO INTERSINDICAL DE ESTATÍSTICA E ESTUDOS SOCIOECONÔMICOS, 2012, p. 52).

13 Nesse estudo específico, as regiões consideradas são: São Paulo, Porto Alegre, Belo Horizonte, Recife, Salvador, Fortaleza e Distrito Federal (DEPARTAMENTO INTERSINDICAL DE ESTATÍSTICA E ESTUDOS SOCIOECONÔMICOS, 2012).

14 O trabalho manual é, segundo Saviani (2007, p. 159), “[...] aquele das profissões manuais para as quais se requeria uma formação prática limitada à execução de tarefas mais ou menos delimitadas, dispensando-se o domínio dos respectivos fundamentos teóricos [...]", e o trabalho intelectual é "[...] aquele das profissões intelectuais para as quais se requeria domínio teórico amplo a fim de preparar as elites e representantes da classe dirigente para atuar nos diferentes setores da sociedade".

15 OCSEUB está localizado a 800 metros do Presídio Professor Jacy de Assis, na cidade de Uberlândia (MG), para a pena de privação de liberdade de adultos.

\section{Manuela Soares Silveira}

manu090993@hotmail.com

Mestrado em Ciências Sociais pela Universidade Federal de Uberlândia (UFU)

Assistente Social da Subsecretaria do Sistema Socioeducativo (Subsis) da Secretaria de Justiça e Cidadania do Distrito Federal (Sejus)

\section{Sejus}

Subsecretaria do Sistema Socioeducativo

Estação Rodoferroviária, Ala Central, Térreo - SAIN

Brasília - Distrito Federal - Brasil

CEP: 70.631-900

\section{Fabiane Santana Previtali}

fabiane.previtali@gmail.com

Doutorado em Ciências Sociais pela Universidade Estadual de Campinas (UNICAMP)

Professora Associado III no Instituto de Ciências Sociais da Universidade Federal de Uberlândia (UFU)

\section{UFU}

Campus Santa Mônica

Av. João Naves de Ávila, 2121 - Santa Mônica

Uberlândia - Minas Gerais - Brasil

CEP: $38.400-902$

\author{
Agência financiadora \\ Não se aplica.
}

\section{Contribuições das autoras}

Manuela Soares Silveira: orientanda de pesquisa de mestrado.

Fabiane Santana Previtali: orientadora de pesquisa de mestrado.

\section{Consentimento para publicação}

Não foram publicados dados pessoais dos sujeitos da pesquisa.

Conflito de interesses

Não há conflito de interesses.

Aprovação por Comitê de Ética e consentimento para participação

Aprovado pelo Comitê de Ética da UFU, CAAE 79971516.6.0000.5152 